\title{
Treatment of the shoulder-hand syndrome with corticosteroids
}

\author{
A. G. MOWAT \\ Departments of Medicine and Orthopaedic Surgery, Rheumatology Unit, \\ Nuffield Orthopaedic Centre, University of Oxford
}

The incidence of the shoulder-hand syndrome is unknown. Certainly the condition is less common since early mobilization of patients after myocardial infarction was instituted 10 to 15 years ago (Graham and Rosen, 1962; Woodhouse, 1968). However, the condition has received scant attention in the British literature (Plewes, 1956) and on the basis of published series of patients would seem to be rather commoner in North America and Europe (Steinbrocker and Argyros, 1958; Johnson and Pannozzo, 1966; Pak, Martin, Magness, and Kavanaugh, 1970).

The cause of the condition has not been clearly determined and its treatment remains empirical. Various authors have recommended intensive physical therapy (Johnson and Pannozzo, 1966), sympathetic blockade, or systemic corticosteroids (Russek, 1958), but the assessment of the results is difficult since partial or complete remission of the condition may occur spontaneously. It therefore seemed valuable to report our findings in three patients with the shoulder-hand syndrome treated with systemic corticosteroids.

\section{Measurement of hand volume}

A method similar to that described by Plewes (1956) was used. The hand was immersed in a beaker of warm water to an indelible line drawn on the skin between the ulnar and radial styloid processes at the wrist, care being taken not to cause venous congestion. The volume of water displaced through a side pipe was measured. Duplicate measurements were made and these confirmed the predetermined accuracy of the method and the small interobserver error of 1 per cent. Further, although there was no diurnal variation in hand volume in normal controls, measurements in the patients were undertaken at $9.00 \mathrm{a} . \mathrm{m}$.

Case 1, a 51-year-old housewife, developed a painful, stiff left shoulder without apparent cause in May, 1971. In July the left hand became swollen, warm, discoloured, and stiff, with limited function. A variety of analgesic antiinflammatory drugs, short-wave diathermy, and exercises failed to alter the symptoms and signs and the patient was transferred to the Nuffield Orthopaedic Centre in December, 1971.

Accepted for publication August 22, 1973.
The patient complained of severe left shoulder pain especially at night and of painful stiffness in the hand all day but worst in the mornings.

\section{Examination}

There was a marked painful restriction of left shoulder movement. The left hand was swollen (volume $445 \mathrm{ml}$; normal right hand $350 \mathrm{ml}$.), the swelling extending over the dorsum of all fingers, and was tender with a bluish-red discolouration. The hand was warm and sweaty. All finger joints had flexion deformities of $45^{\circ}$ and flexion was limited to a further $20^{\circ}$.

The patient's general health was good. The blood pressure was elevated $(180 / 110)$ with Grade II retinal changes. There was no evidence of cardiac or renalo disease. Routine investigations were all normal but the hand radiograph showed slight generalized osteoporosis.

\section{Therapy}

A variety of local measures to the hand, including ice and wax treatment, soft tissue manipulation, the use of a rest splint, and a balanced sling produced no consistent change in symptoms or hand volume. Left shoulder pain was relieved by an injection of hydrocortisone into the sub-acromial bursa. Soluble prednisolone $(60 \mathrm{mg}$./day) was given for 4 days with dramatic reduction in hand volume (Figure) and with substantial improvement in all other hand symptoms and signs. The hand then rapidly returned to its original state although the hand volume remained reduced. Soluble prednisolone $(10 \mathrm{mg}$./day $)$ was re-introduced after 4 days and again there was a steady improvement in symptoms and signs (Figure). The only other therapy was a small dose of thiazide diuretic with potassium supplements to control the hypertension.

\section{Result}

Over the following year symptoms and signs continued to improve (Figure); the dose of prednisolone was steadily reduced and was discontinued after 12 months. There remain flexion deformities of $10^{\circ}$ at the $2 \mathrm{nd}$ and $3 \mathrm{rd}$ proximal interphalangeal joints and at the $2 \mathrm{nd}, 3 \mathrm{rd}$, and 4th distal interphalangeal joints. There are flexion deformities of $45^{\circ}$ at the other finger joints but flexion in all joints is full. The thumb is normal and overall hand function is unaffected. Hand volume $(350 \mathrm{ml}$.) and grip strength $(300 \mathrm{~mm} . \mathrm{Hg})$ are the same on both sides. The skin has a normal texture and appearance. Shoulder movement is normal and there is no muscle wasting. 


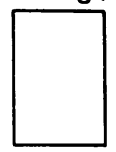

10 5

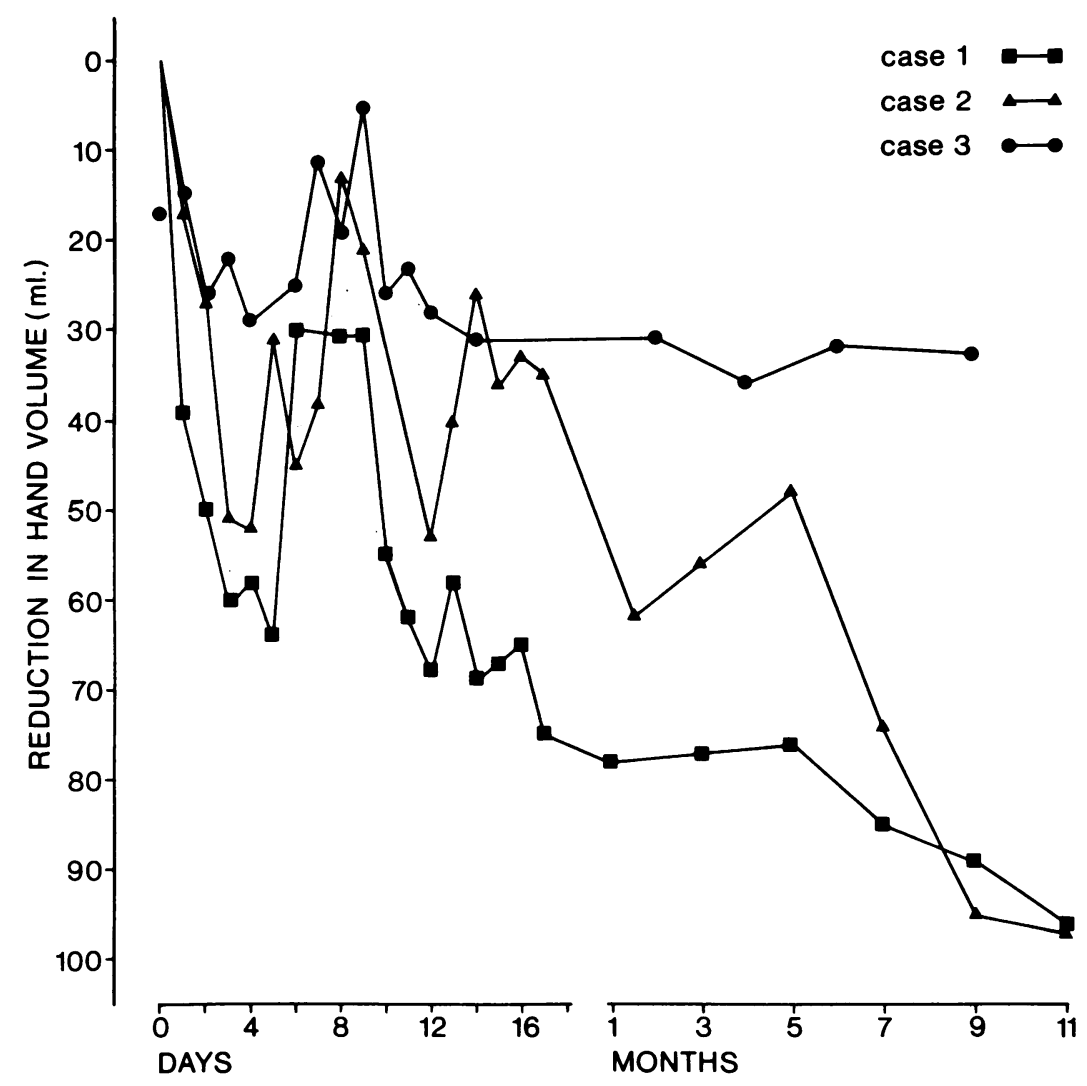

FIG URE Changes in hand volume in the shoulder-hand syndrome

Case 2, a 51-year-old shopkeeper, under treatment for hypertension with methyldopa and thiazide diuretic, developed a mild right hemiplegia in December, 1971. After 3 weeks the right shoulder became painful and stiff, and a few days later the typical changes of the shoulder-hand syndrome appeared in the hand. A variety of physical treatment failed to improve the symptoms and he was transferred to the Nuffield Orthopaedic Centre in February, 1972.

\section{Examination}

The patient complained of severe right shoulder pain and of burning pain, stiffness, and serious functional limitation in the right hand. Right shoulder movements were restricted and painful. The right hand was swollen (volume $548 \mathrm{ml}$.; normal left hand $452 \mathrm{ml}$.), but there was no local tenderness. The skin was cool, sweaty, shiny, and purple. All finger joints had a flexion deformity of $45^{\circ}$ with almost no movement. Neurological examination confirmed residual damage from the hemiplegia. The hypertension was controlled but there were Grade II retinal changes. Routine investigations were normal apart from an elevated blood urea (78 mg./per cent.) and plasma creatinine $(1.4 \mathrm{mg}$./per cent.). Hand radiographs were normal.

\section{Therapy}

After 3 days' rest and the use of a balanced sling had not altered the condition or the hand volume, soluble prednisolone (60 mg./day) was given. The patient's progress then followed a similar course to that of Case 1, improvement in symptoms, signs, and hand volume occurring dramatically and being largely reversed when the drug was stopped. $10 \mathrm{mg}$. of soluble prednisolone per day then caused a more gradual improvement (Figure). Shoulder pain was controlled by an injection of hydrocortisone in the subacromial bursa, and movement encouraged by exercises. Finger movement was encouraged by using a lively splint. 
Result

Over the following 11 months he continued to improve and the dose of prednisolone was progressively reduced and stopped. He had no shoulder pain but abduction remains limited to $80^{\circ}$. There are flexion deformities of $10^{\circ}$ at all the proximal interphalangeal joints but flexion is full. There is weakness of forearm muscles and grip strength is reduced $(160 \mathrm{~mm}$. $\mathrm{Hg}$; left hand $300 \mathrm{~mm}$. $\mathrm{Hg}$ ). There is also residual evidence of the hemiplegia in the face and leg. The appearance of the skin of the hand is normal, and the volume is the same on both sides (451 $\mathrm{ml}$.).

Case 3, a 65-year-old housewife, had been treated with phenobarbitone and phenytoin following an epileptic fit 2 years previously. In Novermber, 1971, she awoke with severe pain and limitation of right shoulder movement. Subsequent investigations suggested that she had had a further epileptic fit in her sleep during which she had sustained considerable damage to the head of the humerus with posterior subluxation of the shoulder. Open reduction of the shoulder was undertaken in February, 1972, and within 2 weeks symptoms and signs consistent with the shoulder-hand syndrome had developed in the right hand. Analgesics, wax therapy, and sling exercises did not alter the symptoms or the range of movement in fingers or shoulder and she was transferred to the Rheumatology Unit in May, 1972.

She continued to complain of a painful burning sensation in the hand accompanied by swelling, sweating, stiffness and disuse. The right shoulder remained painful.

\section{Examination}

Shoulder movement was restricted to $20^{\circ}$ in all directions and all the small finger joints had flexion deformities of $40^{\circ}$ with $30^{\circ}$ active flexion. The hand was shiny, reddishblue, and swollen (volume $312 \mathrm{ml}$.; normal left hand 282 $\mathrm{ml}$.). Her general health was good and routine investigations were normal. The hand radiograph showed marked generalized osteoporosis.

\section{Therapy}

The same programme of corticosteroid therapy was employed with a similar improvement and deterioration in hand appearance, symptoms, function, and volume (Figure). Shoulder and finger movement was encouraged by exercises. Anti-epileptic therapy continued unchanged. Over the following 9 months improvement continued and the dose of soluble prednisolone $(10 \mathrm{mgs} / \mathrm{day})$ was reduced and stopped.

\section{Result}

There is now no shoulder pain but abduction is limited to $65^{\circ}$ and other movements remain a little restricted. Radiographs show marked degenerative changes in the glenohumeral joint. Flexion of the distal interphalangeal joints of the fingers is limited to $30^{\circ}$ but there is no deformity. Hand volume $(279 \mathrm{ml}$.) is the same on both sides, but grip strength is reduced $(140 \mathrm{~mm}$. $\mathrm{Hg}$; left hand $190 \mathrm{~mm}$. $\mathrm{Hg}$ ). The hand appearance is normal and overall function is unimpaired.

\section{Discussion}

A variety of initiating events for the shoulder-hand syndrome have been recognized and most of these can be reconciled with the suggested internuncial pool' mechanism (Steinbrocker, 1968). Many drugs have also been implicated, including phenobarbitone, phenytoin, and izoniazid, and possible biochemical mechanisms have been suggested (Good, Green, and Zarafonetis, 1965; Van der Korst, Colenbrander, and Cats, 1966). Two of our cases were associated with recognized initiating events. In one case the syndrome followed a cerebral vascular accident and in a second case there were possible associations with dislocation of the shoulder and an epileptic fit and its treatment with phenobarbitone and phenytoin. As reported by others (Van der Korst and others, 1960), continuation of drug therapy was associated with a full recovery. Residual shoulder involvement in this patient can be ascribed to severe degenerative changes.

Steinbrocker and Argyros (1958) have described three stages in the shoulder-hand syndrome and have indicated that patients who are treated early are more likely to make a full recovery. The patients described here would all accord with first stage disease, but delay in treatment may explain the residual finger deformity. Further, although these authors have suggested that each stage lasts 3 to 6 months, it is clear that there is considerable individual variation. This variability in natural history and the absence of any controlled trial of treatment makes management difficult. The withdrawal of corticosteroids and the subsequent relapse after a clear therapeutic response in our patients suggests that a natural remission could only account for part of the improvement.

Steinbrocker and Argyros (1958) compared the use of systemic corticosteroids and stellate ganglion blockade in 146 cases and reported that both treatments produced almost complete recovery in 32 per cent. of cases, while a further 50 per cent. showed some improvement. Graham and Rosen (1962) considered corticosteroids superior to stellate ganglion block. Russek, Russek, Doerner, and Zohman (1953) reported improvement with intramuscular cortisone in sixteen out of seventeen cases which had failed to respond to other therapy including stellate ganglion block. It has recently been suggested that ultrasound applied to the stellate ganglion is helpful (Goodman, 1971). Beneficial results have also been reported with intensive physical therapy (Johnson and Pannozzo, 1966), with exercises, continued hand elevation and heating to $105-110^{\circ} \mathrm{F}$. (Plewes, 1956), and with exercises and local hydrocortisone injections (Woodhouse, 1968).

The mechanism of action of corticosteroids in these cases is not clear. Because of excess sympathetic activity there are a variety of vascular changes in the hand associated with increases in capillary permeability, extravasation of plasma components, and pH changes which can explain the findings (Ivins, Nguyen, and Johnson, 1969). Corticosteroids can correct all the abnormalities and may then encourage 
remission by interrupting the neurological 'feedback' which perpetuates the sympathetic outflow (Baxter and Forsham, 1972).

As these cases show, the pain and disability associated with the shoulder-hand syndrome may be severe and despite treatment permanent hand deformity and disability may result. Disability in two cases was increased by the underlying disease, but fortunately no patient developed permanent thickening of the palmar soft tissues although this commonly occurs after 2 or 3 months (Plewes, 1956; Johnson and Pannozzo, 1966). It is suggested that corticosteroids in small dosages are effective in controlling symptoms and should perhaps be used earlier in cases clearly unresponsive to physical therapy.

\section{Summary}

The beneficial effect of systemic corticosteroids on the symptoms and signs of the shoulder-hand syndrome, especially the volume of the swollen hand, in three patients is described. It is suggested that corticosteroids in small dosage should be used earlier in cases unresponsive to physical therapy.

I wish to thank my colleagues for transferring these cases to my care. I am grateful to Mrs. Joan Abery and Dr. B. L. Hazleman for help in standardizing the method of measuring hand volumes, to $\mathrm{Mr}$. G. Bartlett for the Figure, and to Mrs. Margaret Evans for typing the script.

The author is in receipt of a grant from the Arthritis and Rheumatism Council.

\section{References}

BaXter, J. D., ANd Forsham, P. H. (1972) Amer. J. Med., 53, 573 (Tissue effects of glucocorticoids)

Good, A. E., Green, R. A., ANd Zarafonetis, C. J. D. (1965) Ann. intern. Med., 63, 800 (Rheumatic symptoms during tuberculosis therapy. A manifestation of isoniazid toxicity?)

Goodman, C. R. (1971) N.Y.St.J. Med., 71, 559 (Treatment of shoulder-hand syndrome. Combined ultrasonic application to stellate ganglion and physical medicine)

Graham, W., and Rosen, P. (1962) Bull. rheum. Dis., 12, 277 (The shoulder-hand syndrome)

IVIns, J. C., NGuYen, V. V., AND Johnson, E. W. (1969) Minnesota Med., 52, 1115 (Shoulder-hand syndrome)

Johnson, E. W., AND Pannozzo, A. N. (1966) J. Amer. med. Ass., 195, 108 (Management of shoulder-hand syndrome)

Korst, J. K. Van der, Colenbrander, H., And Cats, A. (1966) Ann. rheum. Dis., 25, 553 (Phenobarbital and the shoulder-hand syndrome)

Pak, T. J., Martin, G. M., Magness, J. L., and Kavanaugh, G. J. (1970) Minnesota Med., 53, 507 (Reflex sympathetic dystrophy. Review of 140 cases)

Plewes, L. W. (1956) J. Bone Jt Surg., 38B, 195 (Sudeck's atrophy in the hand)

Russer, H. I. (1958) Med. Clin. N. Amer., 42, 1555 (Shoulder-hand syndrome following myocardial infarction)

- Russex, A. S., Doerner, A. A., And Zohman, B. L. (1953) Arch. intern. Med., 91, 487 (Cortisone in the treatment of the shoulder-hand syndrome following acute myocardial infarction)

STEINBROCKER, O. (1968) Arch. phys. Med., 49, 388 (The shoulder-hand syndrome: present perspective)

and Argyros, T. G. (1958) Med. Clin. N. Amer., 42, 1533 (The shoulder-hand syndrome: Present status as a diagnostic and therapeutic entity)

WoodHOUSE, S. P. (1968) N.Z. med. J., 68, 387 (Shoulder-hand syndrome following myocardial infarction) 